NASA Technical Memorandum 81851

\title{
BOLT-BEARING FATIGUE OF A GRAPHITE/EPOXY LAMINATE
}

John H. Crews, Jr.

JULY 1980

(NASA-TH-81851) BOLT-BEARING FATIGUE OP A
GRAPHITE/EPOXY LAMINATE (NASA) 27 P
HC A03/MFAO1

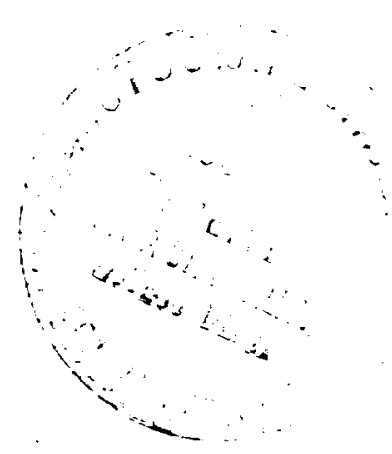




\title{
BOLT-BEARING FATIGUE OF A GRAPHITE/EPOXY LAMINATE
}

John H. Crews, Jr. NASA Langley Research Center Hampton, Virginia 23665

\begin{abstract}
Graphite/epoxy laminates (T300/5208) were tested under bolt-bearing loads for a range of bolt clampup torques and for several test conditions involving water. High clampup torque improved both the static strength and fatigue limit by about 100 percent compared to a simple pin-bearing case, which had no throughthe-thickness constraint. The static strength improvement was explained in terms of failure modes. Bolt clampup also, influenced the hole elongation that developed before failure. For both the static and fatigue tests, the hole elongations were much larger for the low-torque-clampup case than for the pin-bearing case or for tests with moderate clampup torques. Tests in water degraded static bearing strength only slightly, but reduced the fatigue 1 imit about 40-percent below that for tests conducted in air.
\end{abstract}


INTRODUCTION

At present, mechanical fastening is a common foining method for graphite/ epoxy laminates. But fastener holes severely degrade laminate static strength, and the residual strength may be degraded further by fatigue loads. Consequently, reliable joint designs require that this degradation be accurately predicted. To date, most research on fastener holes has dealt with the static strength of laminates with unloaded holes. Relatively little has been done in the area of fatigue strength, especially for loaded holes. The present paper deals with two variables that influence bolt-bearing fatigue strength and life. This study focused on the effects of bolt clampup torque and the effects of water exposure. All of the tests were conducted on single-fastener coupons made from a [0/45/90/-45] 2 s graphite/epoxy (T300/5208) 1aminate. Static and fatigue tests were conducted for a wide range of bolt clampup torques. The static fallures were analyzed to examine the relationship between failure mode and strength. A finite-element analysis was performed to examine the local stresses that cause bearing failures.

During all fatigue tests, the hole elongation due to cyclic loads was monitored until each specimen failed. Ultrasonic methods were used to examine the area around the bolt holes for damage due to cyclic loads. 
SYMBOLS

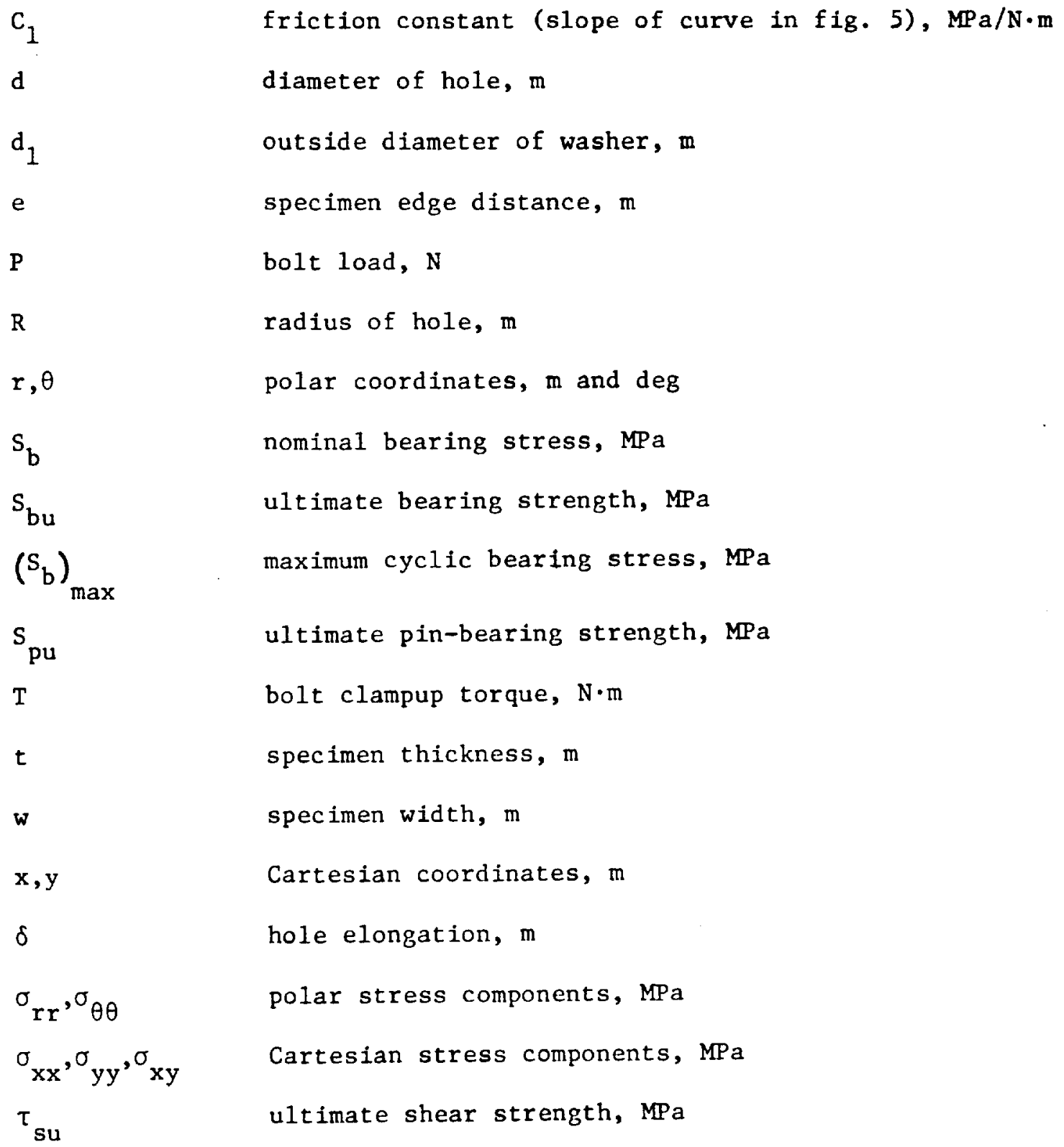

$\mathrm{C}_{1}$

friction constant (slope of curve in fig. 5), $\mathrm{MPa} / \mathrm{N} \cdot \mathrm{m}$ diameter of hole, $\mathrm{m}$ outside diameter of washer, m specimen edge distance, $\mathrm{m}$ bolt load, N radius of hole, $m$ polar coordinates, $m$ and deg nominal bearing stress, MPa ultimate bearing strength, MPa maximum cyclic bearing stress, $\mathrm{MPa}$ ultimate pin-bearing strength, MPa bolt clampup torque, $\mathrm{N} \cdot \mathrm{m}$ specimen thickness, m specimen width, $m$ Cartesian coordinates, $m$ hole elongation, m polar stress components, MPa Cartesian stress components, $\mathrm{MPa}$ ultimate shear strength, MPa 
TEST PROCEDURE

The test specimen configuration and dimensions are shown in figure $1(a)$. A11 specimens were made from a $[0 / 45 / 90 /-45]_{2 s}$ graphite/epoxy (T300/5208) laminate which had a nominal thickness of $2.24 \mathrm{~mm}$. The bolt holes in these specimens were ultrasonically drilled to a diameter slightly larger than the 6.35-mm steel bolt; hole clearances were typically less than $0.15 \mathrm{~mm}$. The specimen width, w, and edge distance, e, were selected for $w / d=8$ and $e / d=4$. These ratios assured bearing failures rather than net-tension or shearout failures [1].

The bolt-loading apparatus is shown in figures $1(\mathrm{~b})$ and $1(\mathrm{c})$. A pair of clevis straps loaded the bolt in double shear; a friction grip reacted the load. The washers (12.7-mm diameter) between the clevis and the specimen distributed the clampup-torque loads over an area around the bolt hole.

Linear variable displacement transducers measured bolt hole elongation. For the static tests, the apparatus in figure $1(d)$ was used to measure the relative displacement between the bolt hole and the clevis. The transducer measured the change in distance between the clevis and a small, stiff wire that rested against the bolt hole, as shown in the figure. To provide clearance for the wire, the bolt and washers were slotted. The measured displacements were attributed entirely to hole elongation, inasmuch as the clevis and bolt deflections were insignificant. An $x-y$ recorder plotted the hole elongation against bearing stress during static tests.

A different approach was used to measure the cyclic hole elongation during fatigue tests. For these tests, a small bar was clamped to the specimen, slightly above the grip line, to replace the wire as shown in figure $1(d)$. Displacements were measured between the clevis and this bar. The cyclic 
displacement was recorded periodically throughout each test using an oscillograph. Because the minimum cyclic load was very small $\left(s_{\min } / s_{\max }=0.05\right)$, the minimum cyclic displacement was assumed to represent only the permanent hole elongation. Accordingly, the permanent hole elongation due to the cyclic loading could be taken directly from the oscillograph trace. All fatigue tests were conducted at a frequency of $10 \mathrm{~Hz}$.

Before testing, the specimens were preconditioned either in laboratory air at room temperature or by soaking them in $363^{\circ} \mathrm{K}$ water for a minumum of 90 days. Using the results in references 2 and 3 , the equilibrium moisture contents were estimated to be about 0.7 percent and 1.8 percent by weight, respectively, for the laboratory-air preconditioning $\left(294^{\circ} \mathrm{K}, 50\right.$-percent $\left.\mathrm{RH}\right)$ and the water-soak preconditioning.

Static strength tests were conducted with air-preconditioned specimens for clampup torques of $0,2.82,5.65,8.48$, and $11.30 \mathrm{~N} \cdot \mathrm{m}$. (The corresponding clampup forces were about $0,2600,5200,7800$, and 10,400 N.) Also, as a reference case, specimens were tested without clampup by assembling the test apparatus without the washers and with a space between the specimen and clevis. This was called the pin-bearing case. Fatigue tests were conducted for clampup levels of $0,2.82$, and $5.65 \mathrm{~N} \cdot \mathrm{m}$ and for the pin-bearing case.

Fatigue tests were also conducted to compare specimens preconditioned by both methods described above. The tests with air-preconditioned specimens were called AA tests if testing was conducted in air, but were called $A W$ tests if conducted in water. Tests in water with presoaked specimens were called WW tests. The fatigue tests in water were all conducted with one clampup torque, $2.82 \mathrm{~N} \cdot \mathrm{m}$. 
For the water immersion fatigue tests, a small tank was placed around the specimen and was filled to a level about 10-mm above the bolt hole. The fatigue cycling started immediately after the tank was filled. The water level was maintained throughout the test. 
RESULTS AND DISCUSSION

\section{Stress Analysis}

The local stresses near the bolt hole were determined with a finiteelement analysis. This two-dimensional analysis was like that in [4] and produced the stress distributions in figure 2. For convenience, these stresses have been normalized by the nominal bearing stress $S_{b}$ (where $\mathrm{S}_{\mathrm{b}}=\mathrm{P} / \mathrm{td} ; \mathrm{P}$ is bolt load, $\mathrm{t}$ is laminate thickness, and $\mathrm{d}$ is hole diameter). Figure $2(a)$ shows stresses along the hole boundary and figure $2(b)$ shows distributions along three planes near the hole. The dashed curves represent the stresses for an infinite laminate.

The stresses in figure $2(\mathrm{~b})$ can be associated with the three basic failure modes for a bearing-loaded hole. The $\sigma_{\mathbf{x x}}$ along the $y$-axis is associated with net-tension failures and the $\sigma_{\mathrm{xx}}$ along the $\mathrm{x}$-axis may produce bearing failures. Shearout failures may occur along $y= \pm R$ planes due to the $\tau_{x y}$ shear stress.

Comparison of the solid and dashed curves in figure 2 shows that the maximum tensile stress at the hole is amplified somewhat by the finite specimen dimensions. However, the bearing stress and the shear stress are nearly equal to the infinite-laminate values. Therefore, test results for this bearing-critical specimen should not be influenced much by its size.

\section{Clampup Effects}

Static strength.- Figure 3 shows typical recordings of hole elongation versus bearing stress for several clampup values. The lowest curve represents the pin-bearing (no-constraint) case. This curve peaks abruptly without stable hole elongation beyond the onset of bearing failure. (Note that these tests 
were conducted with a controlled-displacement rate, $0.01 \mathrm{~mm} / \mathrm{sec}$; therefore, a curve with a negative slope indicates instability.) The bolts for the $T \approx 0$ curve were "finger tightened." The constraint provided by the washer produced only a small increase in the failure-onset strength (the first peak) but caused a large increase in the ultimate bearing strength. The curves for $T=2.82$ and $5.65 \mathrm{~N} \cdot \mathrm{m}$ clampup torques show that clampup can significantly improve ultimate bearing strength. Note, however, that the stable hole elongation was largest for the $\mathrm{T} \approx 0$ case.

Bolt clampup also influenced the failure modes. For example, the pinbearing specimens failed by the well-known bearing mode. Figure 4 (a) shows a typical bearing failure with its characteristic "brooming" near the hole. The accompanying sketch to the right shows the extent of bearing damage. For tests with torqued bolts, most failures occurred by a combination of failure modes consisting of shearout under the washer and bearing failure beyond the washer, as shown in figure 4(b). For high clampup torques, several specimens failed by the shearout-tension-bearing failure mode shown in figure $4(\mathrm{c})$. However, the shearout-bearing mode in figure $4(\mathrm{~b})$ was the typical failure mode and occurred for cases involving even small clampup torques. In general, clampup appeared to suppress the simple bearing failure mode and, instead, produced a combined failure mode at a higher load level.

The results of static tests are summarized by figure 5, which shows bearing strength plotted for a range of clampup levels. Each symbol represents the average of three tests. The curves for failure-onset and ultimate strength both show the expected trend of higher strengths for larger clampup levels. Similar trends were shown in [5]. The 50-percent improvement in ultimate strength for the $\mathrm{T} \approx 0$ case, compared to the pin-bearing case, shows 
the effects of simple bearing mode suppression. The largest clampup torque improved the ultimate strength by more than 100 percent compared to the pinbearing case.

Friction was believed to contribute to the strength improvement due to clampup. As a result, tests were conducted to measure the force needed to slide the washers against the specimen. These friction forces, expressed as equivalent bearing stresses, are presented also in figure 5 for the range of clampup torques. Note that the friction curve has about the same slope as the ultimate strength curve for torques larger than about $7 \mathrm{~N} \cdot \mathrm{m}$.

An equation for ultimate bearing strength was developed to investigate the potential benefit due to bolt clampup. This equation was based on the assumption that failure occurs by the shearout-bearing mode in figure $4(\mathrm{~b})$. For failure criteria, the average bearing stress and the average shearout stress were both assumed to equal the corresponding laminate strength.

$$
s_{b u}=s_{p u}+\sqrt{\left(d_{1} / d\right)^{2}-1} \tau_{s u}+c_{1} T
$$

The $\mathrm{S}_{\mathrm{pu}}$ is the pin-bearing strength, $\tau_{\text {su }}$ is the laminate shear strength, $C_{1}$ is the friction curve slope, and $d_{1}$ is the washer diameter. The present $\mathrm{S}_{\mathrm{pu}}$ value of $525 \mathrm{MPa}$ and the $\tau_{\text {su }}$ from [6] were substituted into equation (1) to obtain the dash-dot curve in figure 5. As expected, the ultimate strength data are below the dash-dot curve because equation (1) neglects the stressconcentration effects and failure sequence effects. However, the data agree reasonably well with the dash-dot curve for large clampup torques.

Hole elongation due to cyclic loading. - As explained earlier, the hole elongation was monitored throughout each fatigue test. Figure 6 shows permanent 
hole elongation versus load cycles for different clampup levels. The four cases in this figure were selected because they have similar fatigue lives; note, however, that their stress levels are different. For the pin-bearing case, the $400 \mathrm{MPa}$ fatigue stress did not noticeably elongate the hole before the specimen failed. By contrast, for the $T \approx 0$ case, the $600 \mathrm{MPa}$ stress elongated the hole by about $1 \mathrm{~mm}$. For this case, the washers provided enough constraint to improve the residual static strength but apparently had much less influence on hole elongation. The curves for $T=2.82 \mathrm{~N} \cdot \mathrm{m}$ and $5.65 \mathrm{~N} \cdot \mathrm{m}$ show that clampup reduced hole elongation, compared to the $\mathrm{T} \approx 0$ case, despite the higher stress levels involved. These data are included in figure 7. The dashed curves in figure 7 represent a $0.2-\mathrm{mm}$ hole elongation and the solid curves represent fatigue life. As in subsequent figures, each symbol represents the average of three tests. For the pin-bearing case, the 0.2-mm elongation developed late in the fatigue life; the $T=5.6 \mathrm{~N} \cdot \mathrm{m}$ case shows similar behavior. However, the $\mathrm{T} \approx 0$ case shows significant hole elongation before failure. This trend is like that described previously for figure 3 , which showed that the largest static hole elongation also occurred for the $\mathrm{T} \approx 0$ case.

Effect of Water

As previously explained, the water-exposure tests on air-preconditioned specimens were called the AW tests. Those conducted on water-preconditioned specimens were called WW tests. Also, the tests in air with air-preconditioned specimens were called AA tests. The AA tests provided a reference case to evaluate the water-exposure effects. Recall that all these tests were conducted with one clampup level, $2.82 \mathrm{~N} \cdot \mathrm{m}$. 
Figure $8(a)$ presents the AA test results. These reference curves are based on the same test conditions as used in the clampup tests and, therefore, could have been included in an earlier figure. For the present discussion, the $\delta=0.2 \mathrm{~mm}$ curve was assumed to represent the onset of permanent hole elongation. As a result, this curve indicates a hole-elongation threshold stress of about $600 \mathrm{MPa}$ for the AA tests.

Figure $8(\mathrm{~b})$ presents the water-exposure curves for $\delta=0.2 \mathrm{~mm}$. The AW and WW curves indicate hole-elongation thresholds of about $450 \mathrm{MPa}$ and $350 \mathrm{MPA}$, respectively. These are about 25- and 40-percent lower than the $600 \mathrm{MPa}$ threshold for the AA reference case. Similar curves are shown in figure 8 (c) for $\delta=0.4 \mathrm{~mm}$. Beyond $10^{6}$ cycles, the $\mathrm{AW}$ and $\mathrm{WW}$ curves are again about $25-$ and 40-percent below the AA curve, respectively.

Figure $8(d)$ compares the SN curves for the three cases. This figure shows that water exposure degraded the fatigue strength but had very little effect on static strength. The SN curves are nearly identical to the curves for $\delta=0.4 \mathrm{~mm}$ in figure $8(\mathrm{c})$. This similarity suggests that the fatigue failures were probably caused by hole elongation. Apparently, the water decreased fatigue strength by decreasing the hole-elongation resistance. As a result, large clampup torques that suppress hole elongation might offset the effects of water.

Figure 9 shows photographs and ultrasonic C-scan images of specimens after 20,000 cycles of $600 \mathrm{MPa}$ bearing stress for the three test conditions. The purpose of this figure is to compare delamination damage near the hole after the holes have elongated somewhat. Although barely noticeable in the photographs, hole elongations of $0.09 \mathrm{~mm}, 0.25 \mathrm{~mm}$, and $0.30 \mathrm{~mm}$ were recorded for the AA, AW, and WW conditions, respectively. Despite these differences in 
hole elongation, the C-scan results show about the same delamination for all three conditions. This observation suggests that the different hole elongations were probably caused by a very localized effect, perhaps one that was confined to the bearing interface.

There are several possible explanations for the effects of water on hole elongation resistance. For example, the water could have flushed debris away from the bearing damage site and thereby continuously exposed undamaged material to the cyclic bolt loads. Perhaps the water continuously degraded a thin surface layer at the bearing interface as the hole elongated. Also, the water may have reduced friction and therefore increased the portion of the load transferred by the bearing. 
CONCLUDING REMARKS

Graphite/epoxy laminates (T300/5208) were tested under bolt-bearing loads using a simple clevis fixture with a $6.35-\mathrm{mm}$ steel bolt and $12.7-\mathrm{mm}$ washers. The study consisted of two test series. In the first ser1es, static and fatigue tests were conducted for a range of bolt clampup torques. In the second series, the fatigue behavior was compared for specimens tested in air and in water.

Bolt clampup had a significant effect on both the static strength and the fatigue limit. Each was improved by as much as 100 percent compared to the pin-bearing case which has no through-the-thickness constraint. The static strength improvement was explained by observed differences in failure modes. A simple equation was developed to estimate bearing strength for high bolt clampup torques.

Bolt clampup also significantly influenced the bolt hole elongation. In static tests, the smallest hole elongations at failure were observed in the pin-bearing tests, and the largest elongations were observed in tests with a very small clampup. High clampup resulted in intermediate hole elongations. A similar trend was observed during the fatigue tests; the small clampup case had noticeably more hole elongation before fatigue failure than did the pinbearing case. But high clampup torques virtually eliminated hole elongation due to fatigue.

Water had little effect on static bearing strength but reduced the fatigue limit by about 40 percent compared to tests conducted in air. The water reduced the threshold stress needed to permanently elongate the hole during cyclic loading. This reduced hole-elongation resistance was probably responsible for the reduced fatigue limit. These tests were conducted with a 
moderate clampup torque. Tests with higher clampup torques may show less degradation due to water. 


\section{REFERENCES}

[1] Hart-Smith, L. J., "Bolted Joints in Graphite-Epoxy Composites," NASA CR-144899, National Aeronautics and Space Administration, June 1976.

[2] McKagne, E. L., Jr., Reynolds, J. D., and Halkias, J. E., "Moisture Diffusion in Fiber Reinforced Plastics," Transactions, American Society of Mechanical Engineers, Jan. 1976, pp. 92-95.

[3] Springer, George S., and Shen, Chi-Hung, "Moisture Absorption and Desorption of Composite Materials," AFML-TR-76-102, Air Force Materials Laboratory, 1976.

[4] Hong, C. S., and Crews, John H., Jr., "Stress-Concentration Factors for Finite Orthotropic Laminates with a Circular Hole and Unaxial Loading," NASA TP-1469, National Aeronautics and Space Administration, May 1979.

[5] Stockdale, J. H. and Matthews, F. L., "The Effect of Clamping Pressure on Bolt Bearing Loads in Glass Fiber-Reinforced Plastics," Composites, Jan. 1976, pp. 34-38.

[6] "Advanced Composites Design Guide. Volume I - Design." Third Edition (Second Revision). Air Force Flight Dynamics Laboratory (Contract No. F33615-74-C-5075), Sept. 1976. 


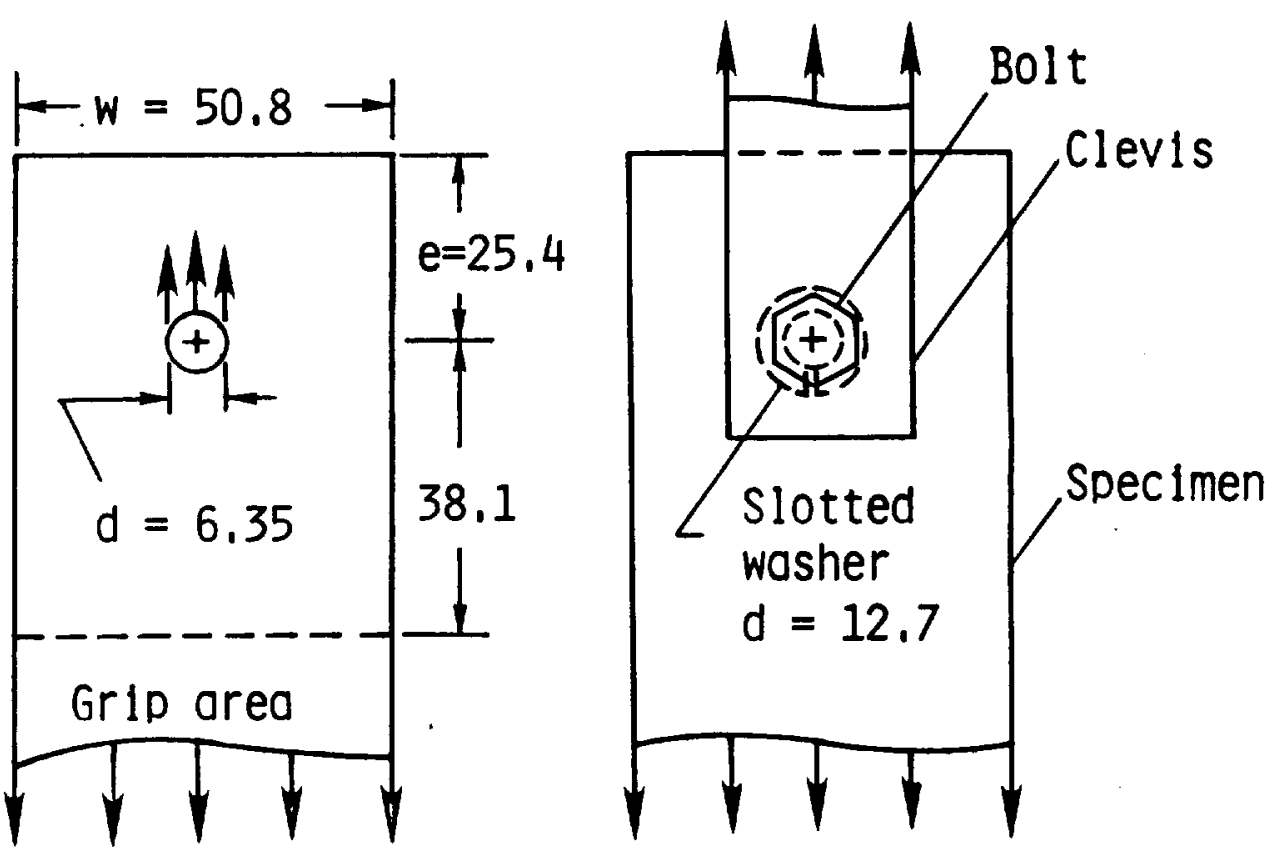

(a) Dimensions (mm),

(b) Loading (front view).
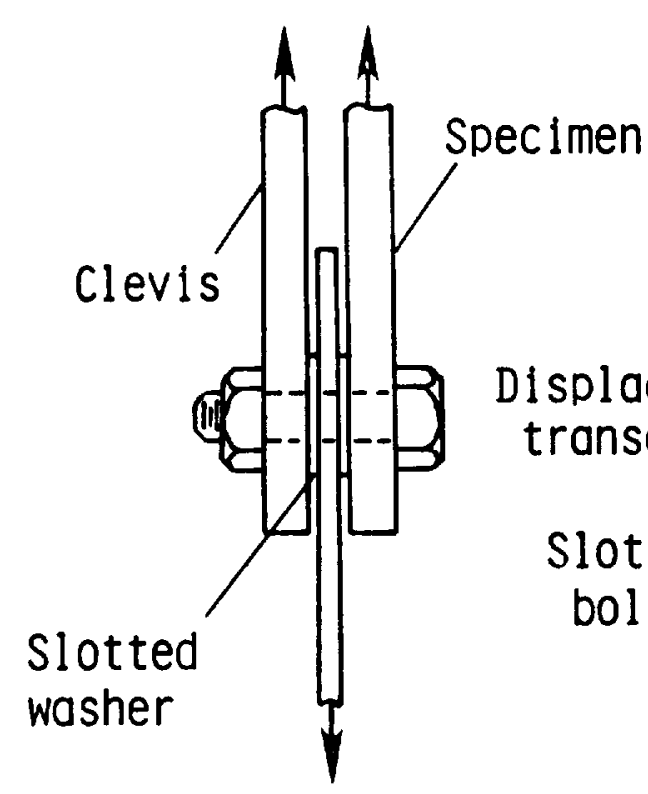

(c) Loading (side vlew).

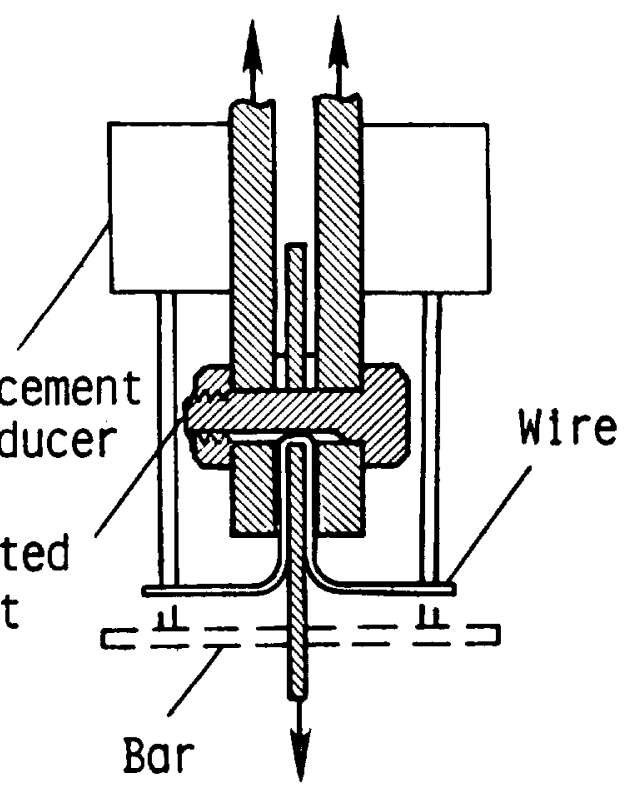

(d) Instrumentation.

Figure 1.- Specimen and test apparatus. 


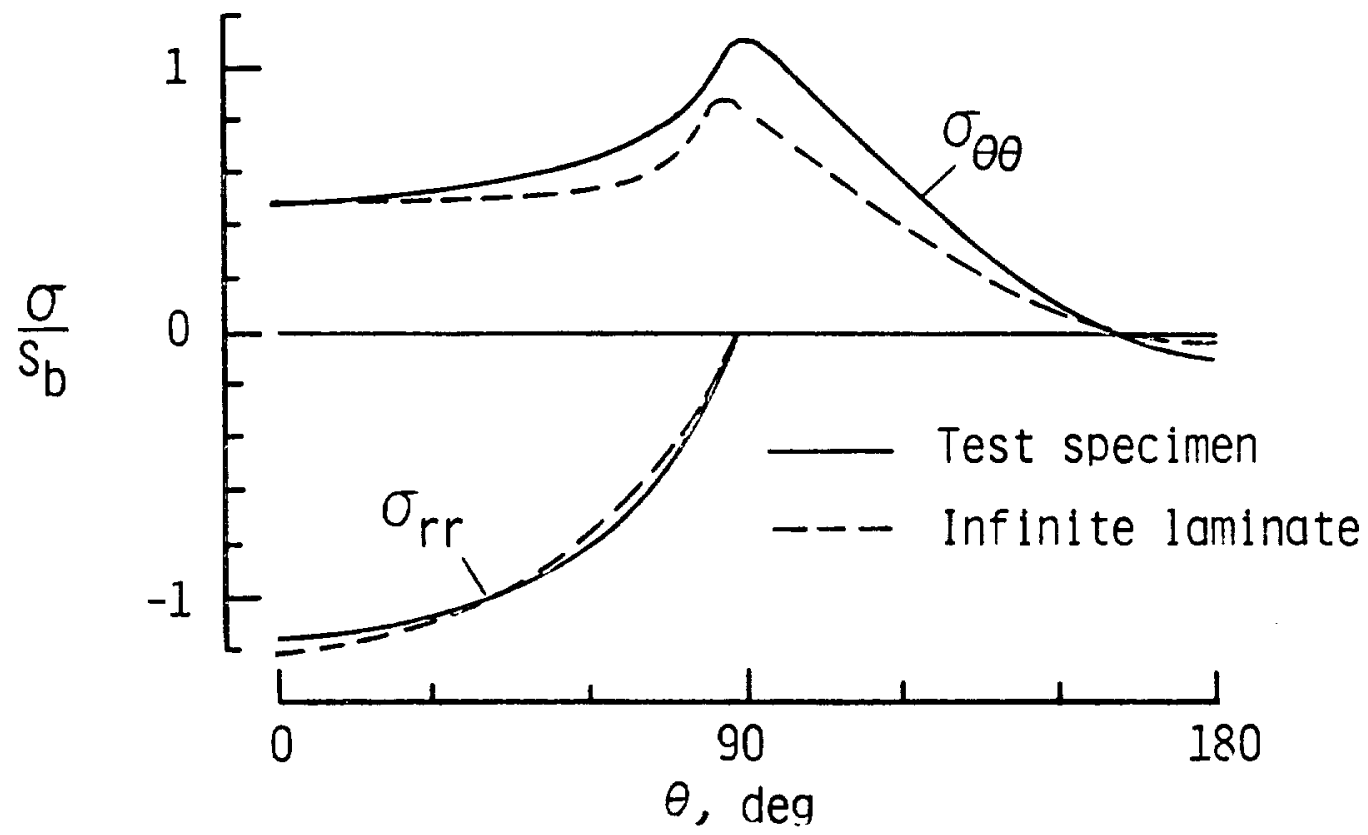

(a) Along the hole boundary.

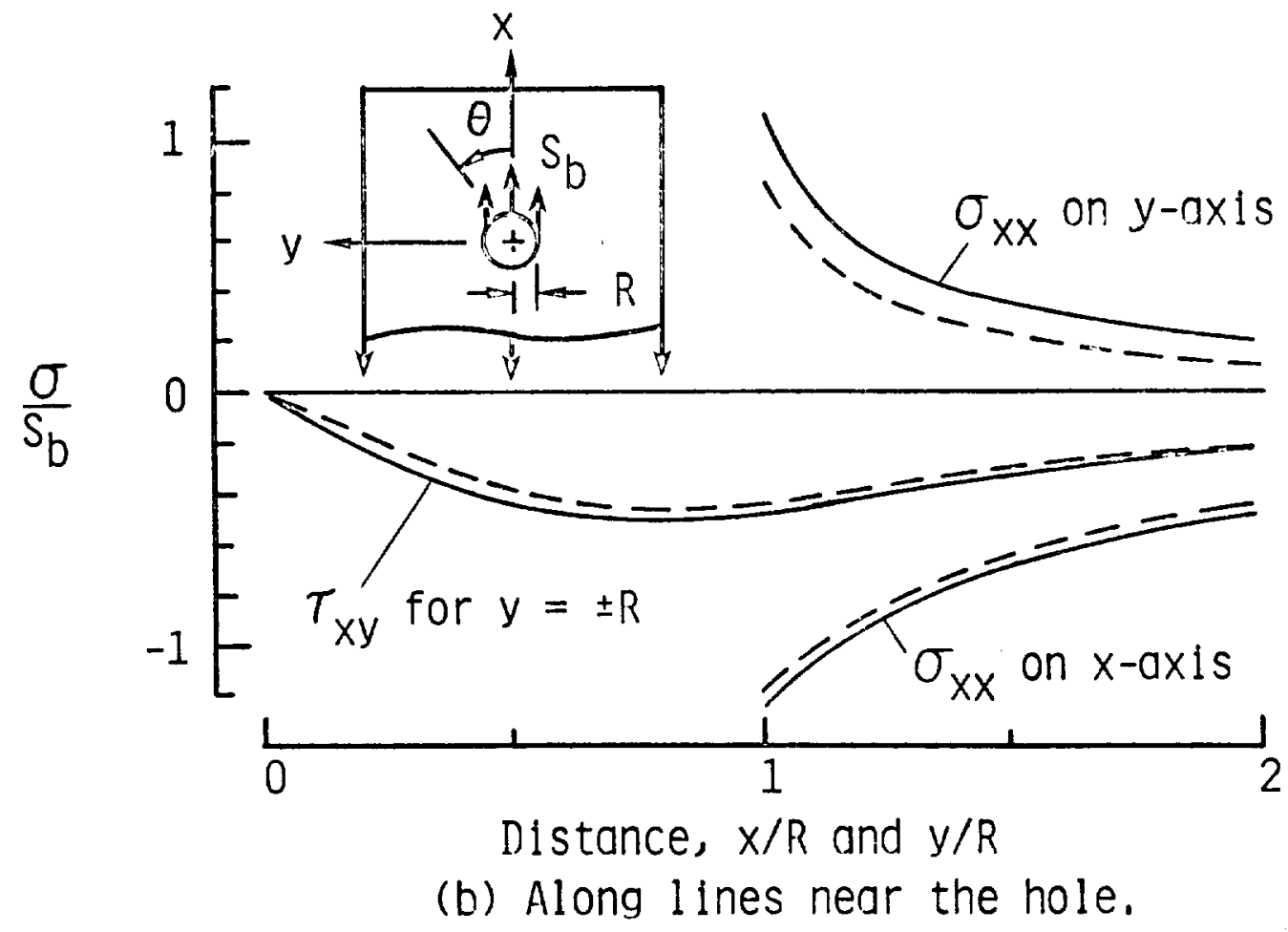

Figure 2.- Stress distributions near pin-loaded hole. 


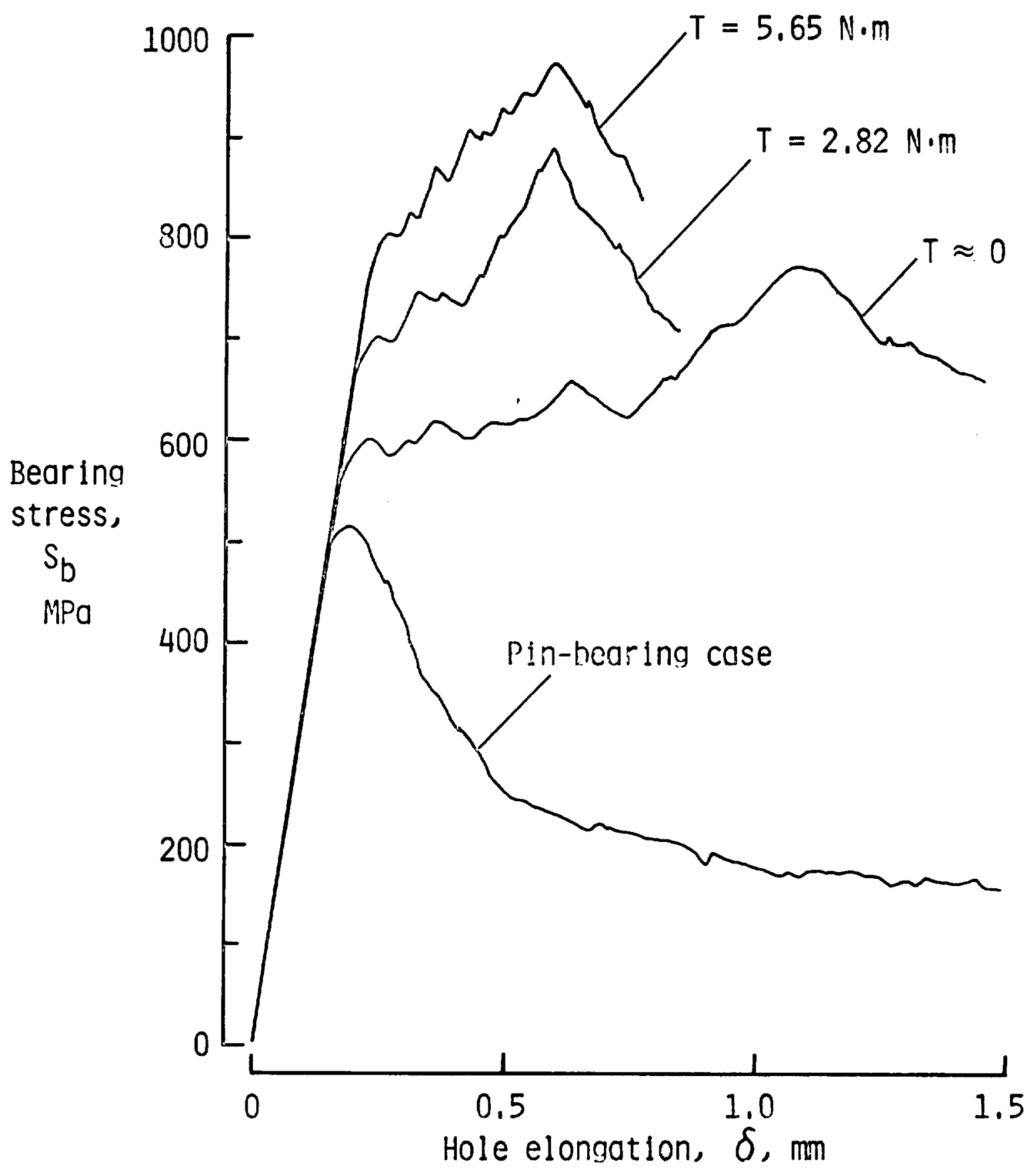

Figure 3. - Static hole elongation for several clampup conditions. 

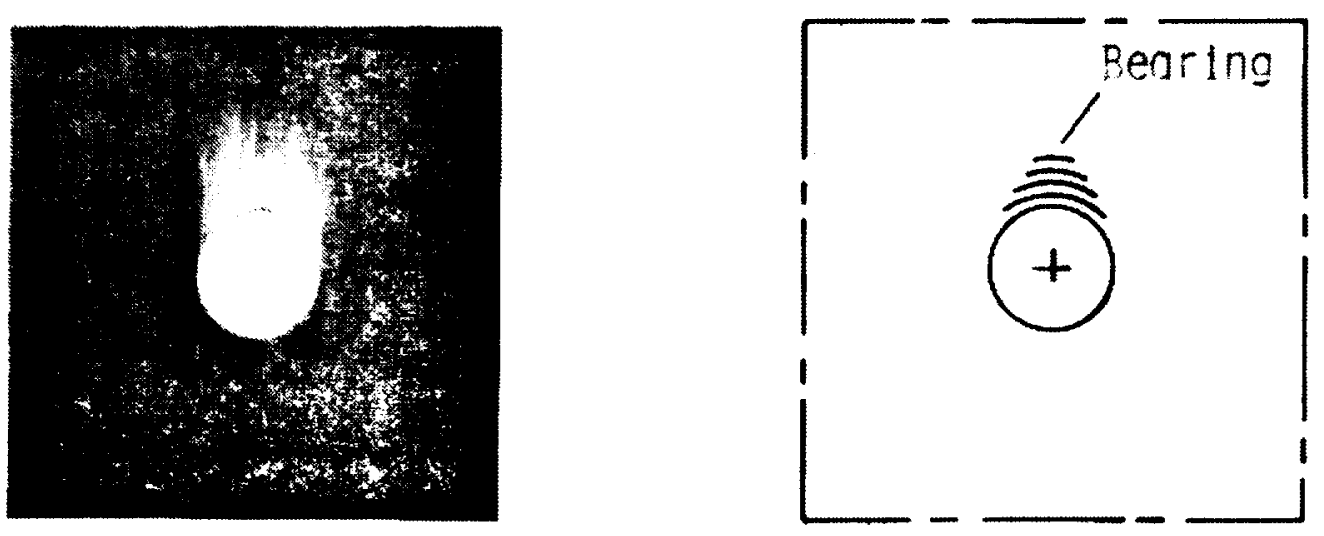

(a) Bearlng fallure mode (oin bearing).
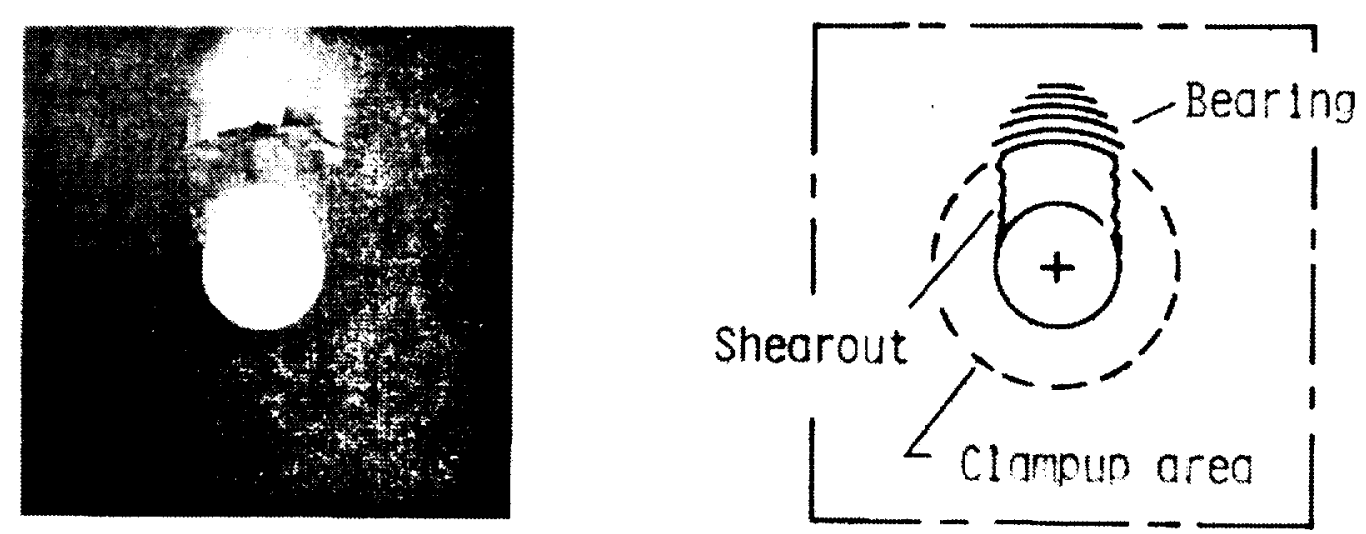

(b) Shearout-bearing follure (moderate clampup).
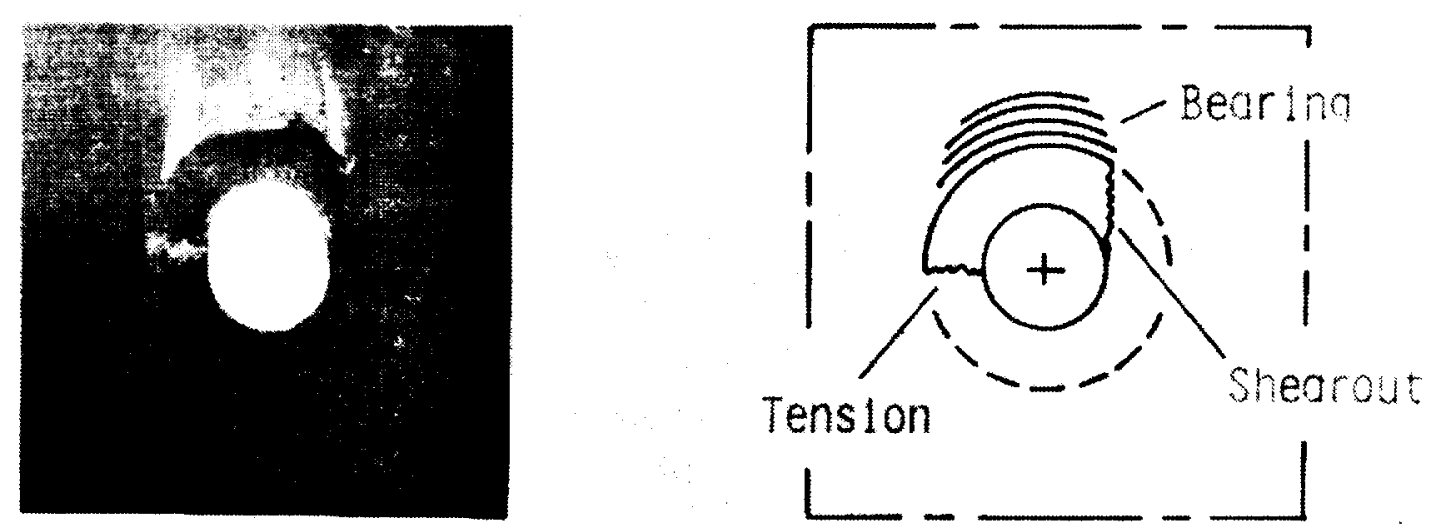

(c) Sheorout-tenston-bearing fallure mode thigh clommin:

Figure 4. - Static fallure modes. 


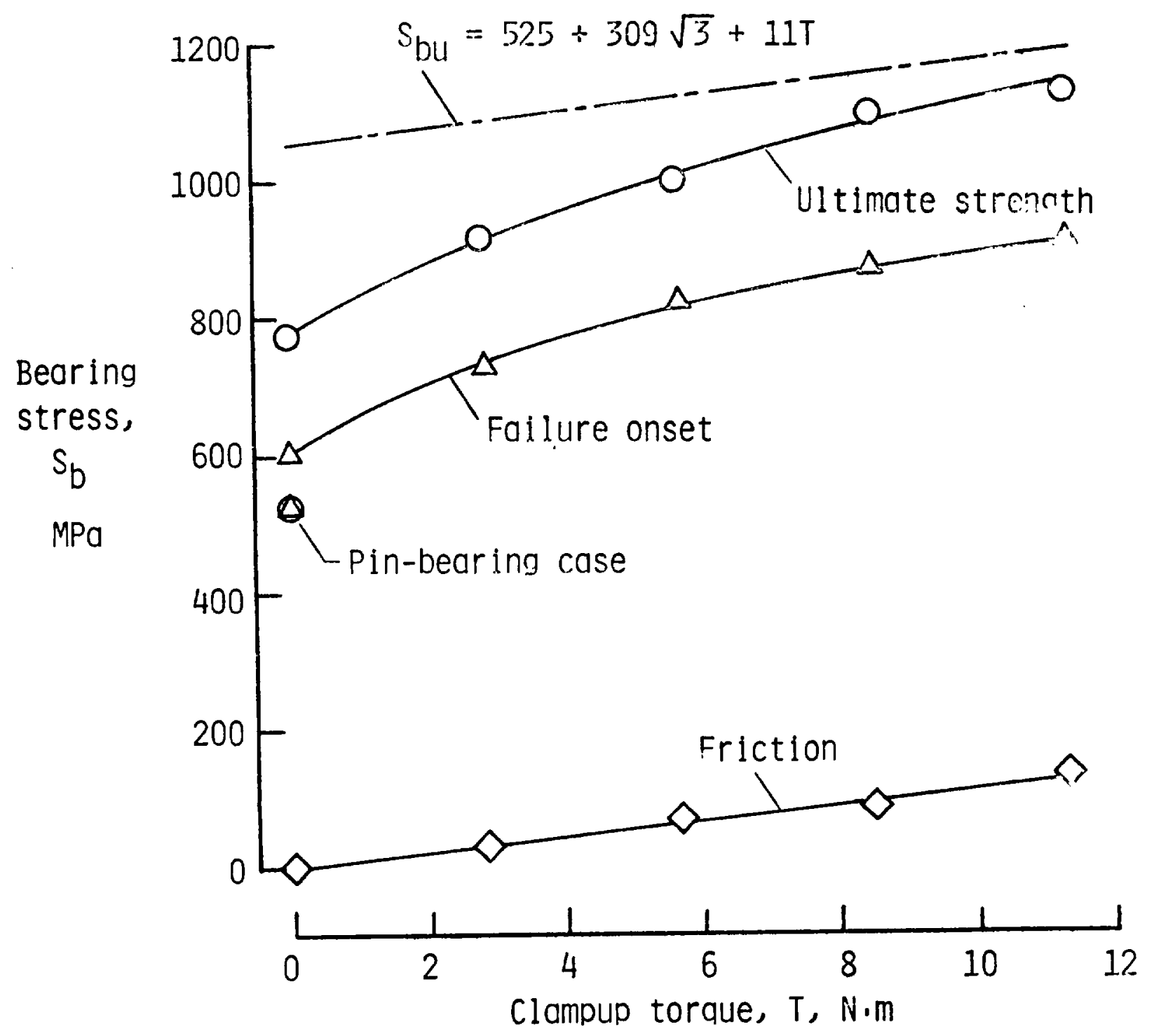

Figure 5.- Static bearing strength for range of clampup torque. 


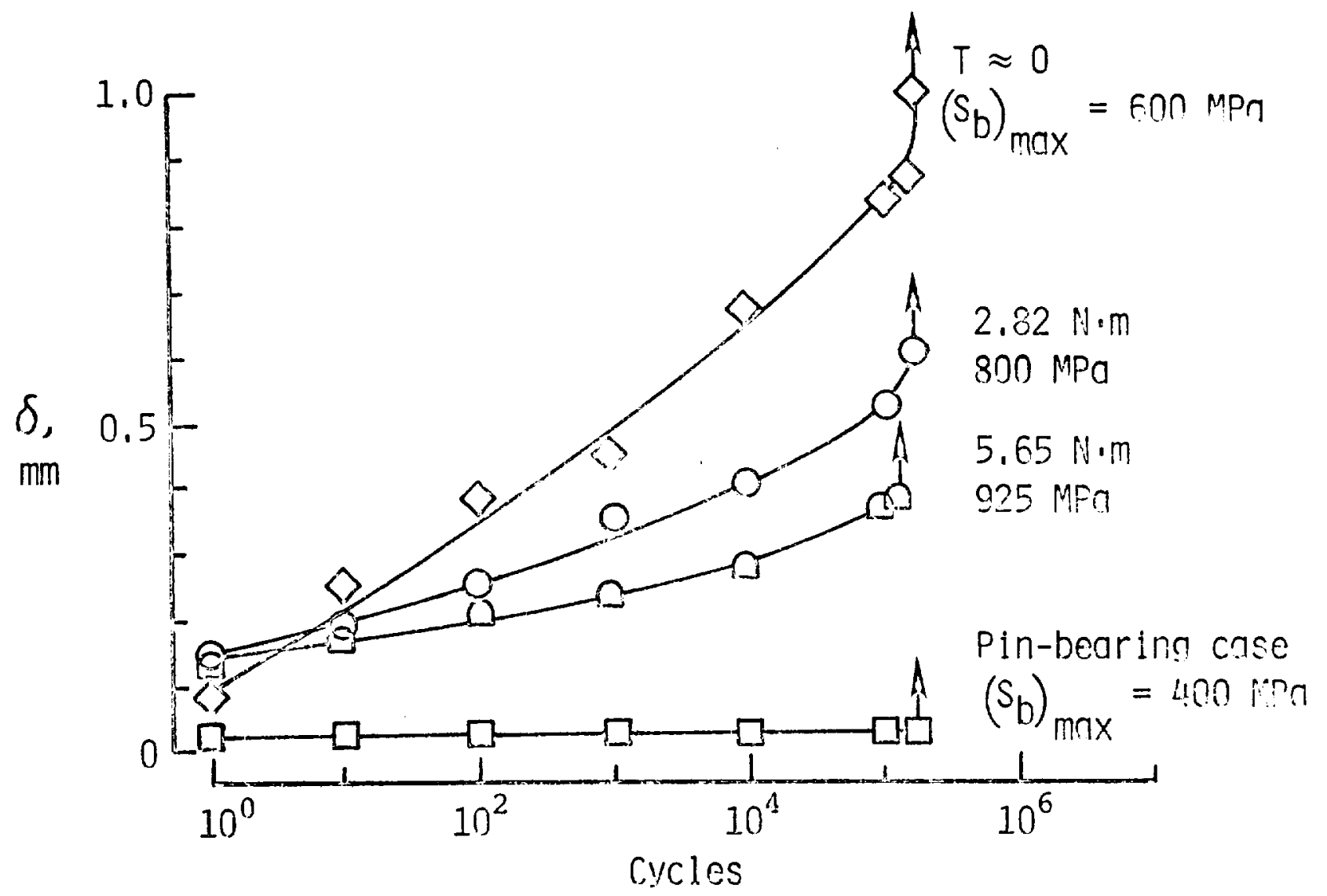

Figure 6.- Hole elongation curves for several clampup cases. 


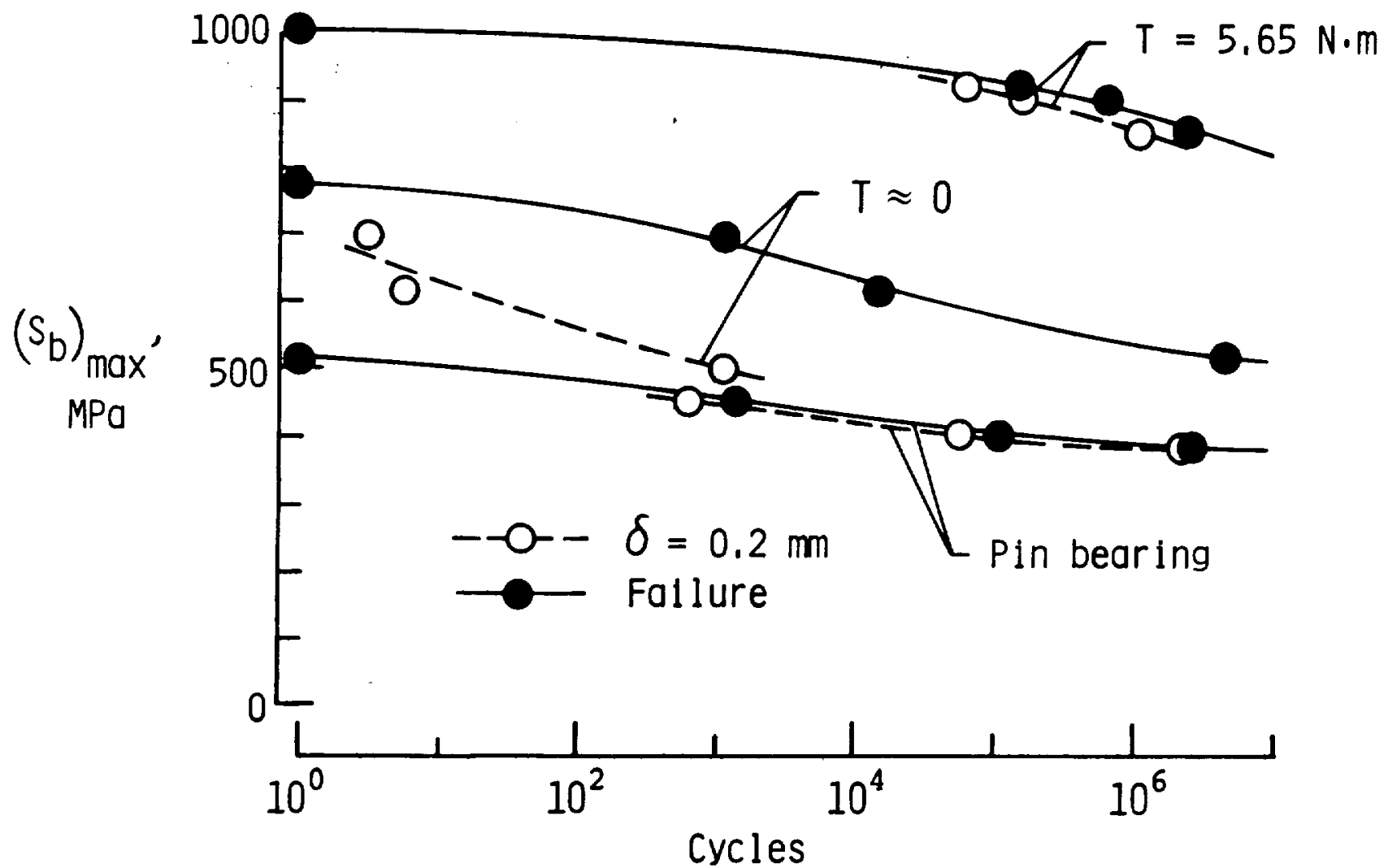

Figure 7.- Hole elongation curves and SN curves for several clampup conditions. 


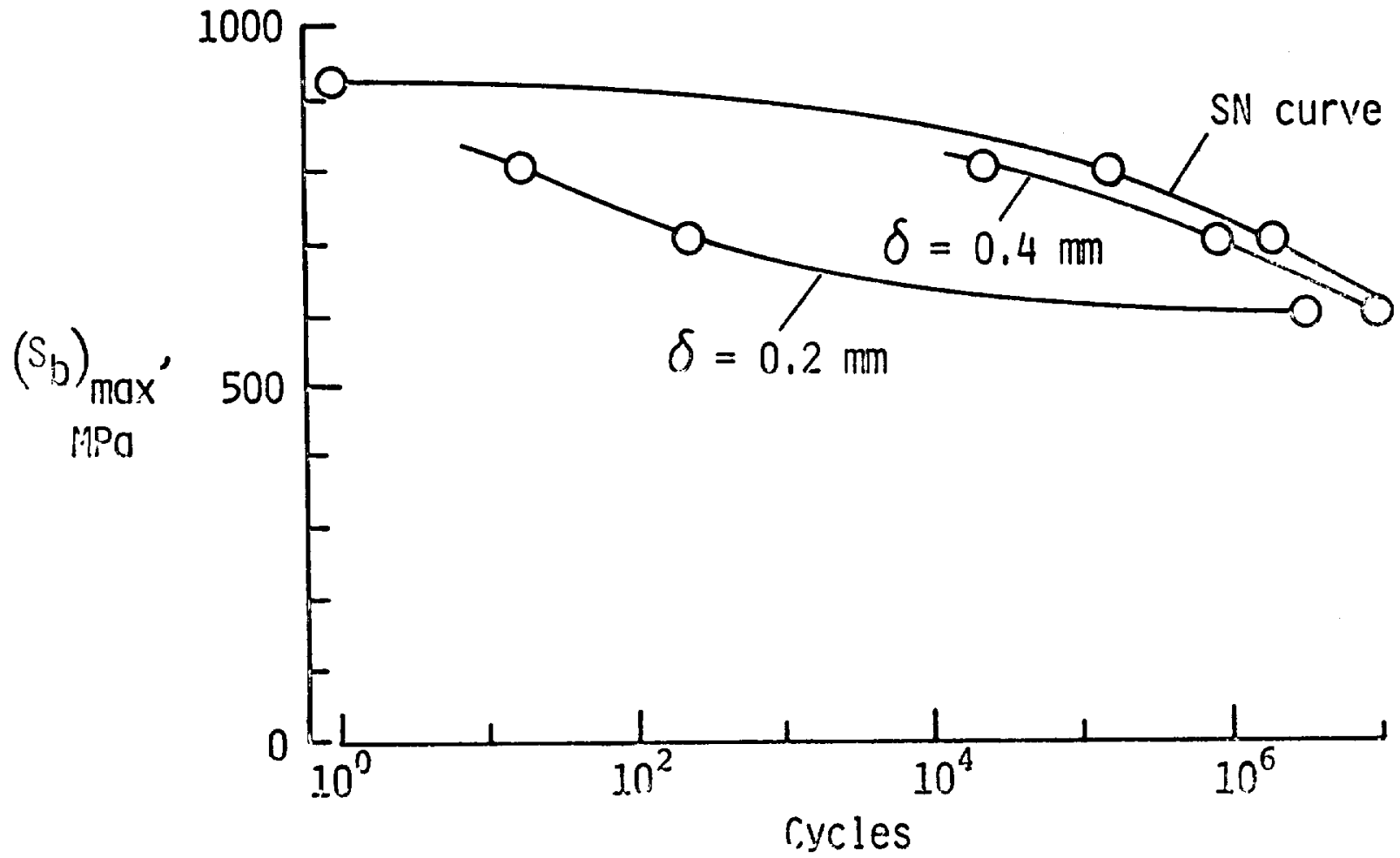

(a) An tests.

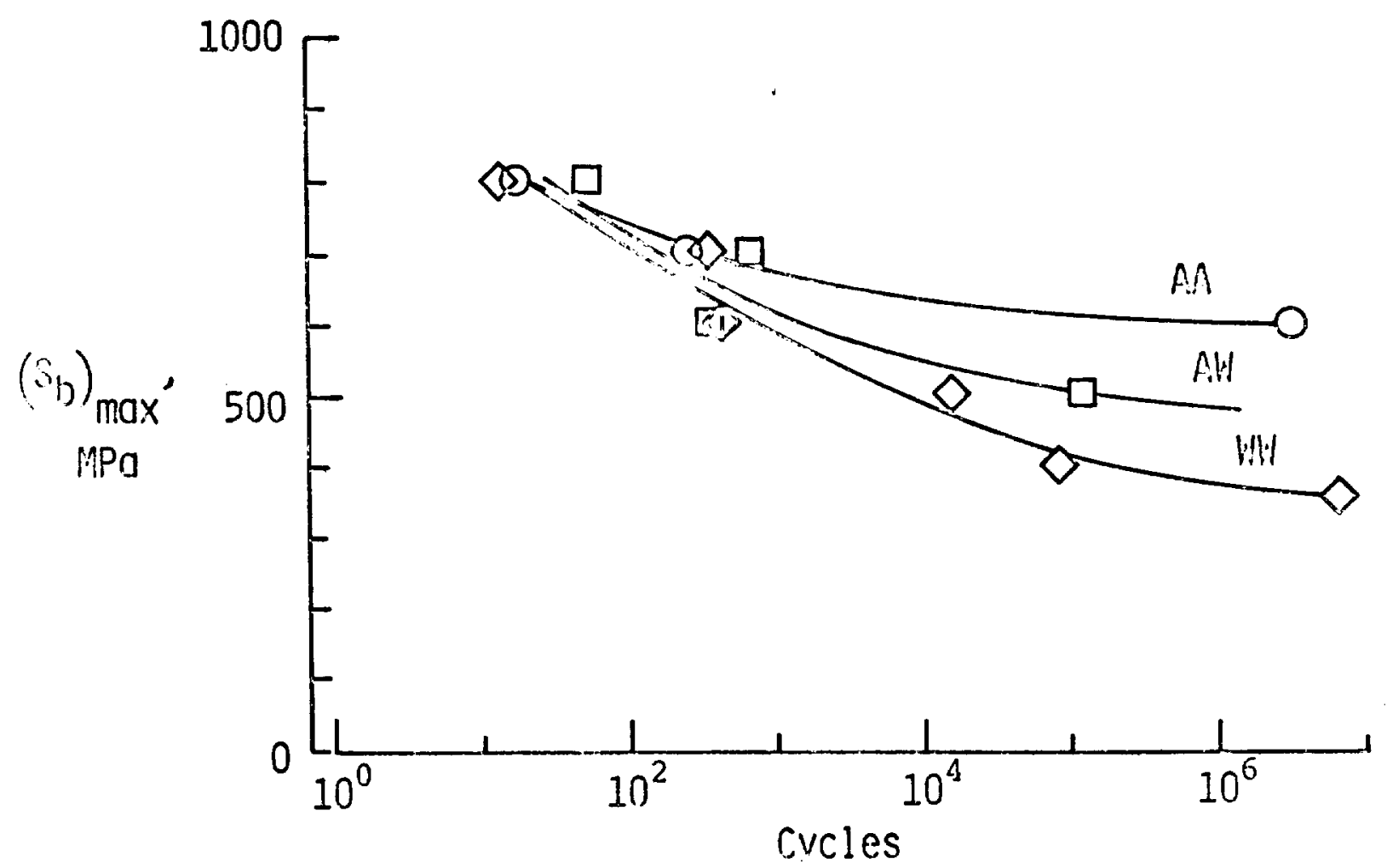

(b) $\delta=0.2 \mathrm{~mm}$.

Figure 8.- Comparison of results from tests in air and water, $T=2.82 \mathrm{~N} \cdot \mathrm{m}$. 


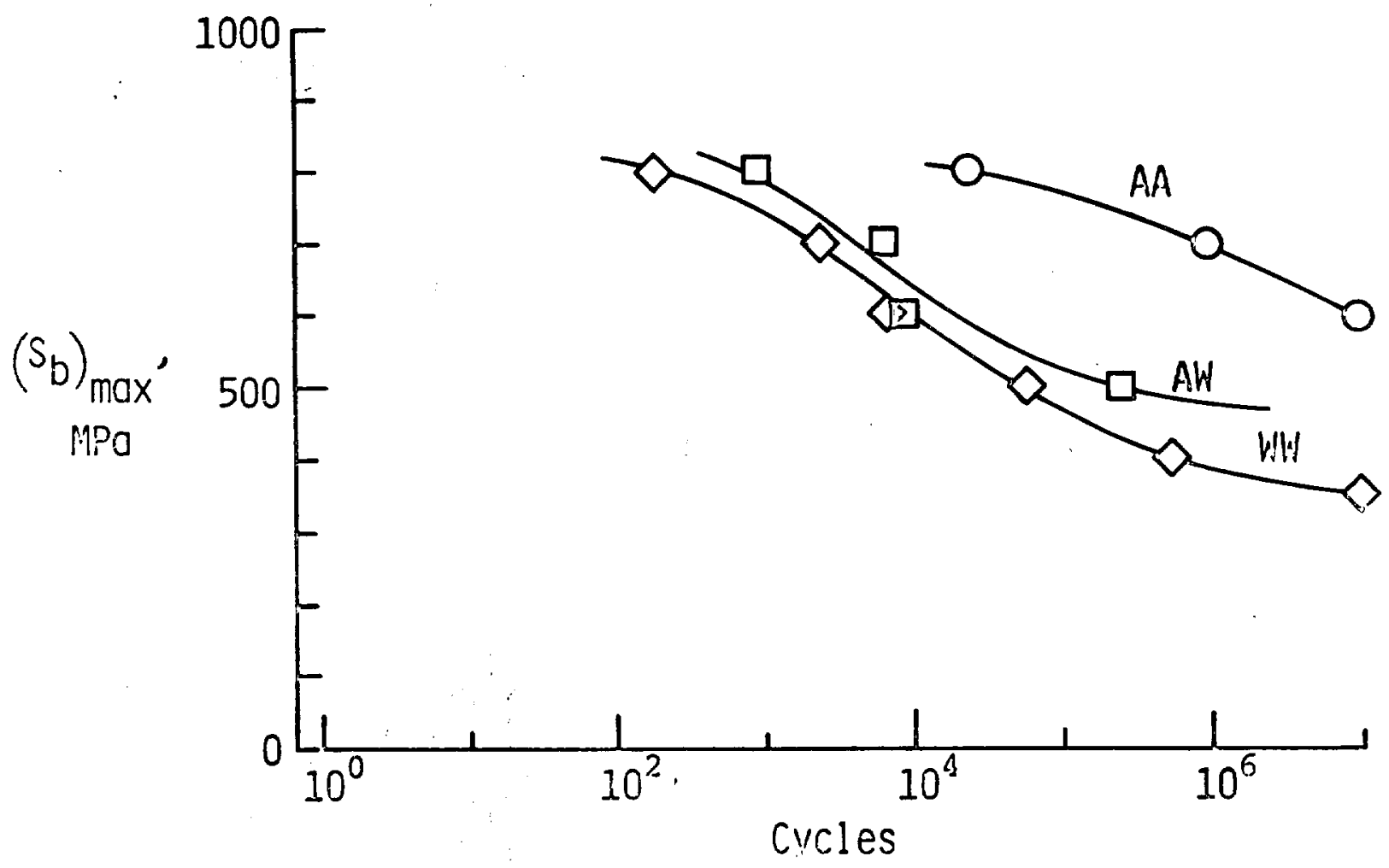

(c) $\delta=0.4 \mathrm{~mm}$.

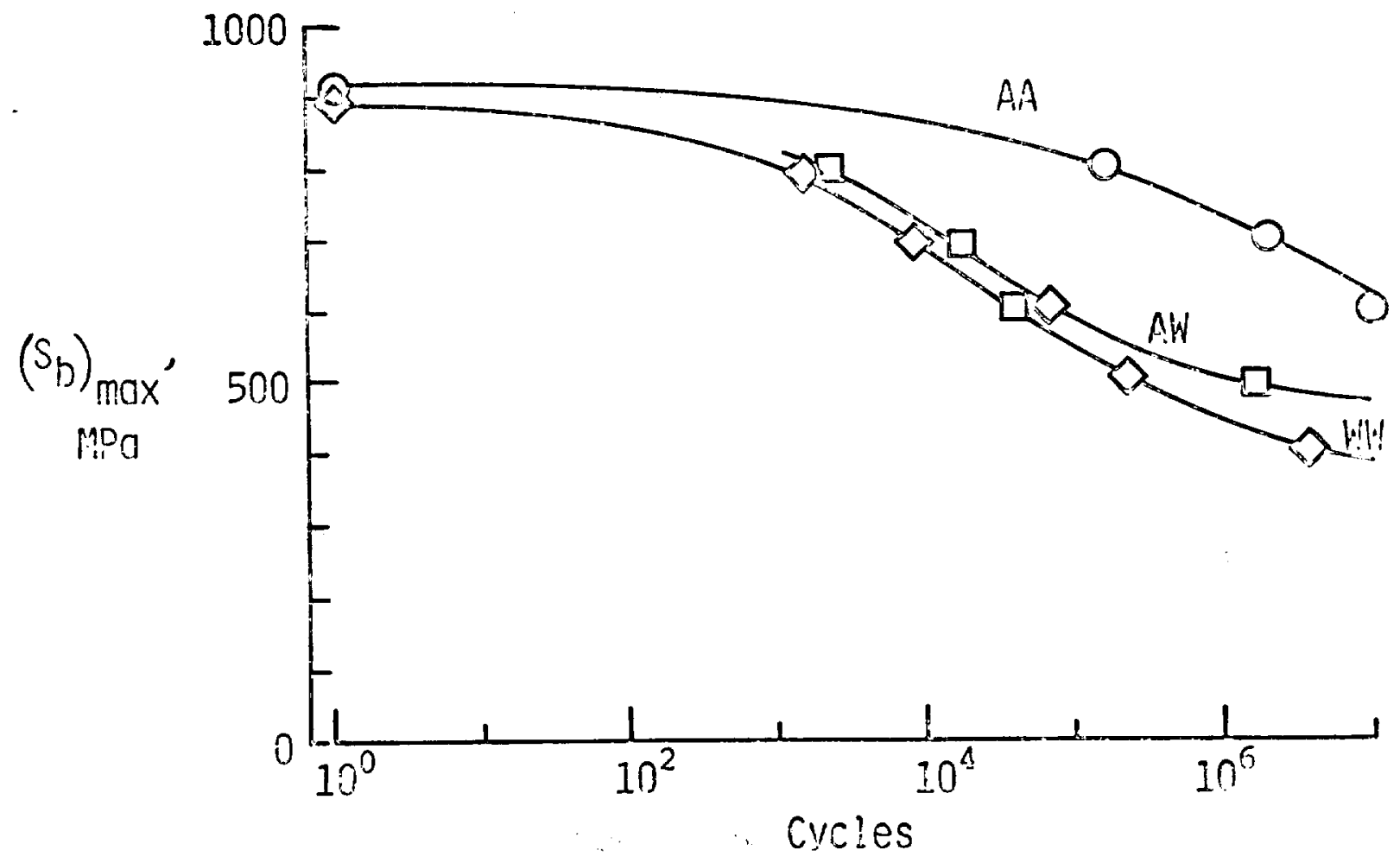

(d) Sin curves,

Figure 8.- Concluded. 

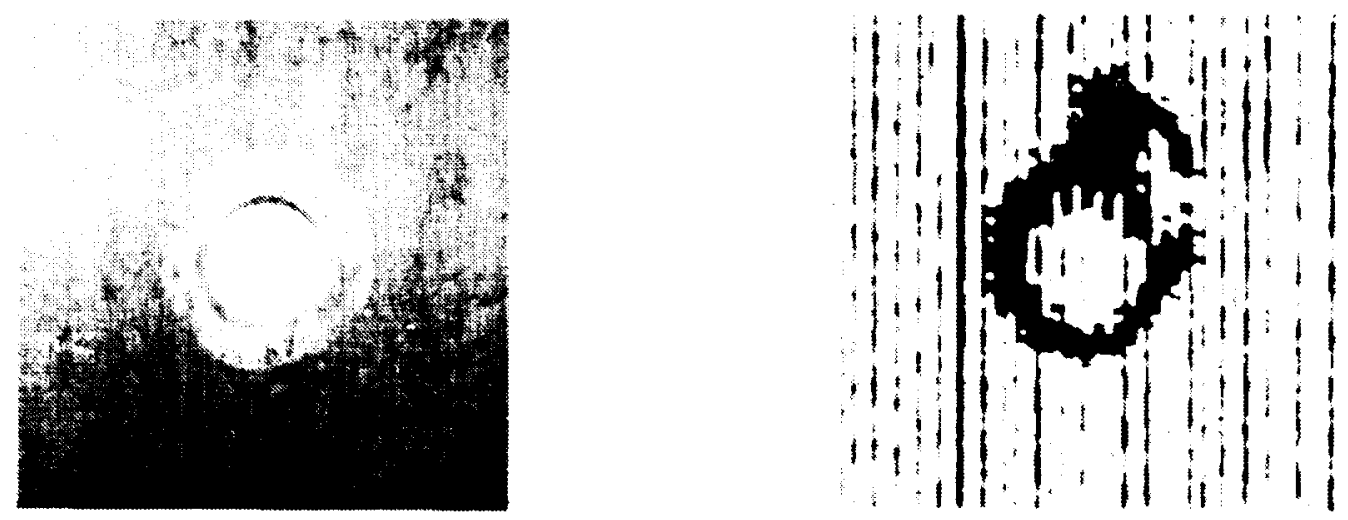

(a) AA test.
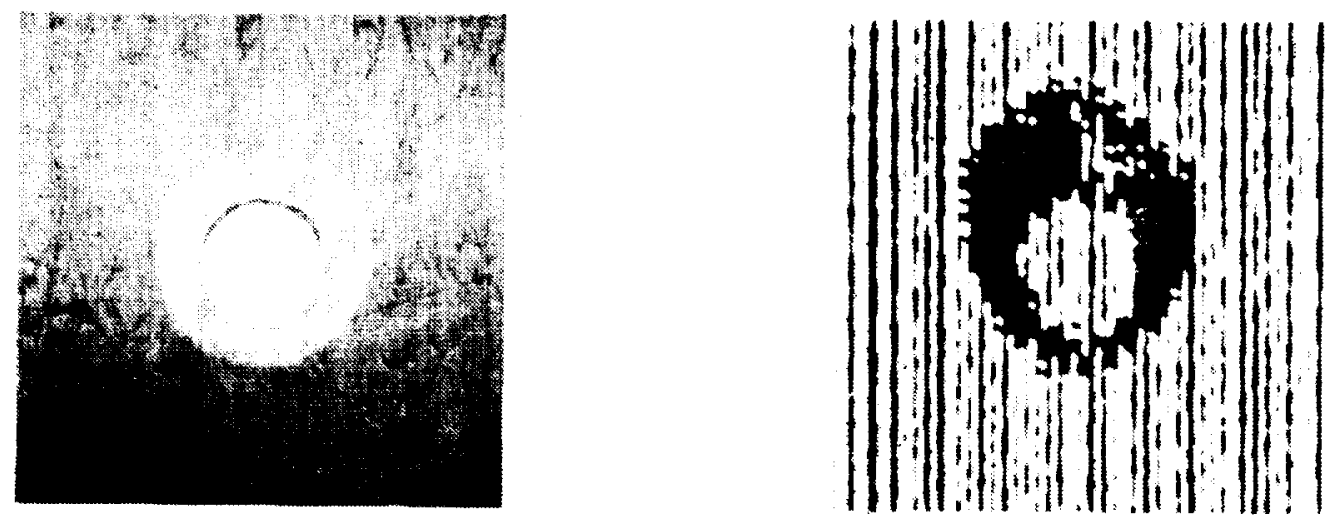

(b) AW test.
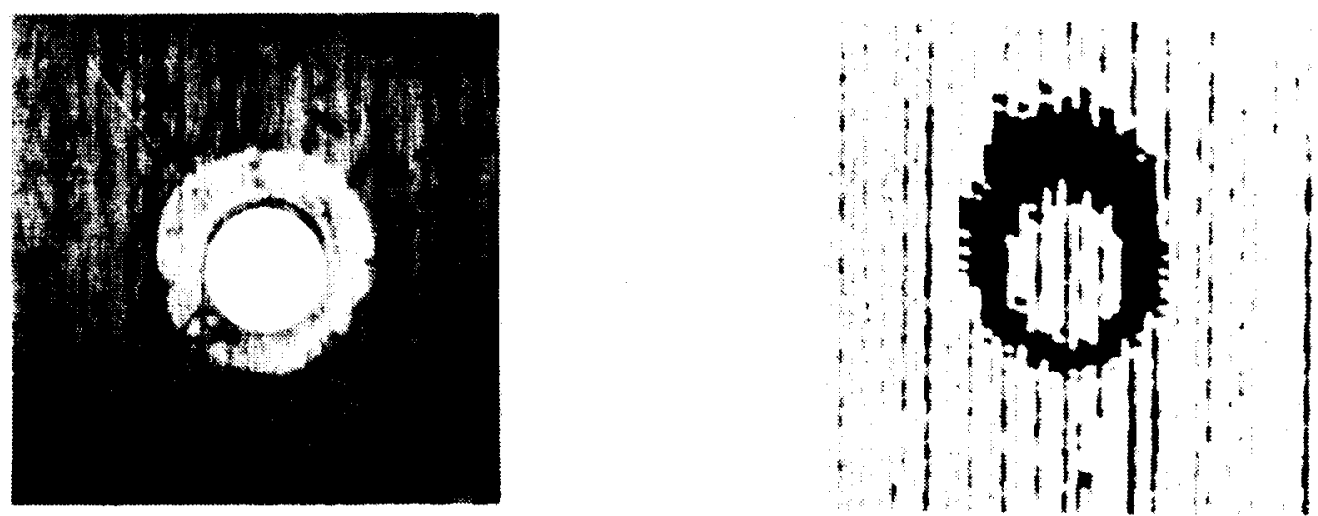

(c) WW test.

Figure 9.- Specimen photographs and ultrasonic C-scan imades after 20,000 cycles, $\left(S_{b}\right)_{\text {max }}=600 \mathrm{Mca}$
$T=2.82 \mathrm{~N} \cdot \mathrm{m}$. ORIGINAL PAGE IS OF POOR QUALITY 


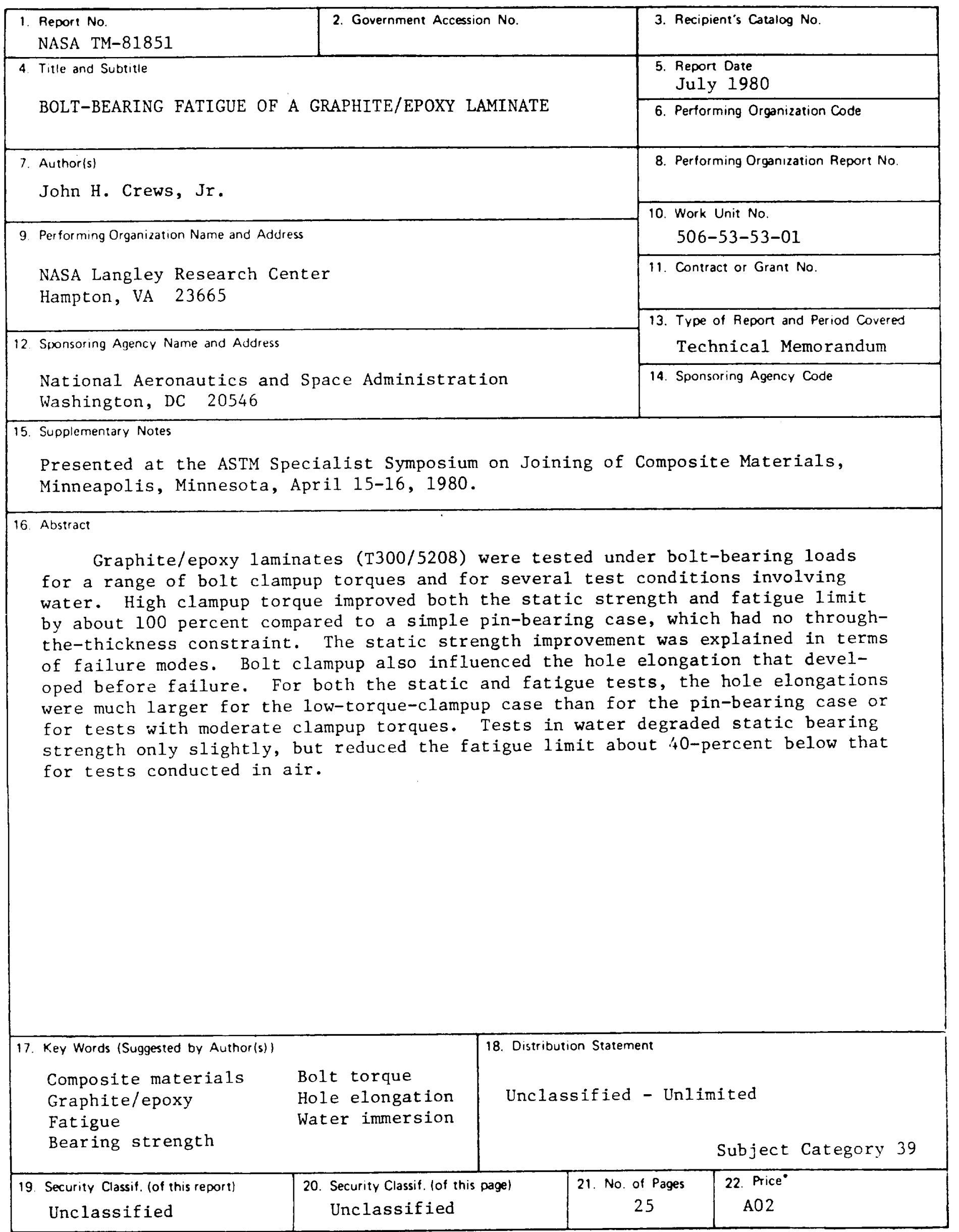

* For sale by the National Technical Information Service. Springleld. IIgina 22161 
1 